\title{
Environmental damage in XXth century architecture
}

\author{
I. Ozga ${ }^{1,2}$, A. Bonazza ${ }^{1}$, F. Tittarelli ${ }^{3}$, E. Bernardi ${ }^{2}$, O. Favoni ${ }^{3}$, \\ N. Ghedini ${ }^{1,4}$, L. Morselli $^{2}$ \& C. Sabbioni ${ }^{1}$ \\ ${ }^{1}$ Institute of Atmospheric Sciences and Climate, ISAC-CNR, \\ Bologna, Italy \\ ${ }^{2}$ Department of Industrial Chemistry and Materials, \\ University of Bologna, Italy \\ ${ }^{3}$ Department of Materials and Environmental Engineering and Physics, \\ Ancona, Italy \\ ${ }^{4}$ Department of Pharmaceutical Sciences, University of Bologna, Italy
}

\begin{abstract}
It has been recognized that many modern buildings undergo rapid deterioration, especially in areas with high air pollutant concentrations. It is assumed that the deposition of gaseous multi-pollutants and aerosols plays a major role in causing the deterioration of monuments and built cultural heritage in European cities. While the deterioration process due to air pollutants and particle deposition is well studied in stones, particularly limestone, sandstone and granite, in the case of cement materials the subject has yet to be explored.

This work focuses on the investigation of the impact of air multipollutants on concrete architecture in current urban atmospheres. The diagnosis of surface layers considering location of buildings is a major issue in this research. To this end laboratory analyses have been preformed on samples from buildings exposed in different urban areas: Centennial Hall of 1913 (Wroclaw, Poland, close to a power station); Chiesa dell'Autostrada del Sole of 1963 (Florence, Italy, close to the motorway) and Casa Galleria Vichi of 1911 (Florence city centre). The samplings were carried out taking into account different levels and parts of the buildings, in washed out, sheltered and partly sheltered areas. The characterization of collected surface layers and cement mortar samples was performed using a range of analytical methods, including optical and scanning electron microscopy, x-ray diffraction, ion chromatography, induced coupled
\end{abstract}


plasma-optical emission spectroscopy, differential and gravimetric thermal analysis and CHNSO elemental analysis.

The quantitative results from the experimental work will be presented and discussed, in order to achieve an exhaustive picture of the main causes leading to concrete deterioration in the buildings under study.

Keywords: air pollution, cultural heritage, cementitious material, sulfation.

\section{Introduction}

Environmental ageing of monuments and historical building has been subject of several studies in recent years, however, few works are dedicated to buildings from the XXth century. It is demonstrated that deterioration of the buildings, especially in urban areas, is caused by wet and dry deposition of gaseous pollutants and aerosols. Laboratory and exposure test of cement hydraulic mortars and also analyses of exposed concrete construction indicate that $\mathrm{SO}_{2} / \mathrm{H}_{2} \mathrm{SO}_{4}, \mathrm{CO}_{2} / \mathrm{H}_{2} \mathrm{CO}_{3}, \mathrm{NO}_{\mathrm{x}} / \mathrm{HNO}_{3}$ have the most important role in surface deterioration [1-3]. Acidic gases, in fact, interact with cement components, firstly causing crystallization of salts on outer surfaces, which are subsequently leached away, eroding the surface and increasing porosity of the material [4].

The deposition of air multipollutants on areas sheltered from rain wash out leads formation of damage layer. This phenomenon is well documented for stones and marbles decay [5], however very few data are available for cementitious materials [1]. Studies dealing with damage layer on natural stone have shown that gypsum, due to deposition of atmospheric sulphur compounds, is the main component. Deposition of atmospheric aerosols, spores, pollen and dust, on gypsum constituting damage layer, causes darkening (blackening) of the facade and so called black crust [5].

The black damage layer on cement-based mortars is modestly known in monuments and construction. The analyses of black crusts from the indoor walls of a concrete tunnel indicate gypsum as the main components with embedded particulate matter produced by fuel combustion. In particular, embedded in gypsum matrix were aluminosilacate particles from coal combustion and carbonaceous particles with oil-derived fuels origin [1].

The objective of the present work is centred on cement material-environment interaction, focusing on the investigation of the damage of the XXth century architecture induced by air multipollutants in different urban areas in Europe.

\section{Materials and methods}

In order to evaluate the environmental damage in the XXth century architecture, laboratory analyses have been performed on the samples from three buildings: Centennial Hall (fig. 1a)), Casa Galleria Vichi (fig. 1b)), Chiesa dell'Autostrada del Sole (fig. 1c)) exposed in different urban atmospheres. The Centennial Hall represents building from very high polluted area: it is located in Wroclaw (Poland), $5 \mathrm{~km}$ away from a coal power station. This building is a landmark in the history of reinforced concrete architecture, designed in 1913 by Max Berg. 
In 2006 it was added to UNESCO's prestigious list of the World Heritage Sites. Casa Galleria is located in the historical centre of Florence, characterized by high traffic emission. This palace was built in 1911 in the style of art nouveau, according to plan of Giovanni Michelazzi. The third site is Chiesa dell'Autostrada del Sole, located between autostrada del Sole and the A11 Firenze-Mare highway. It was built in 1960 based on plans by Giovanni Michelucci, frequently cleaned and restored: last restoration work was performed two years before sampling.
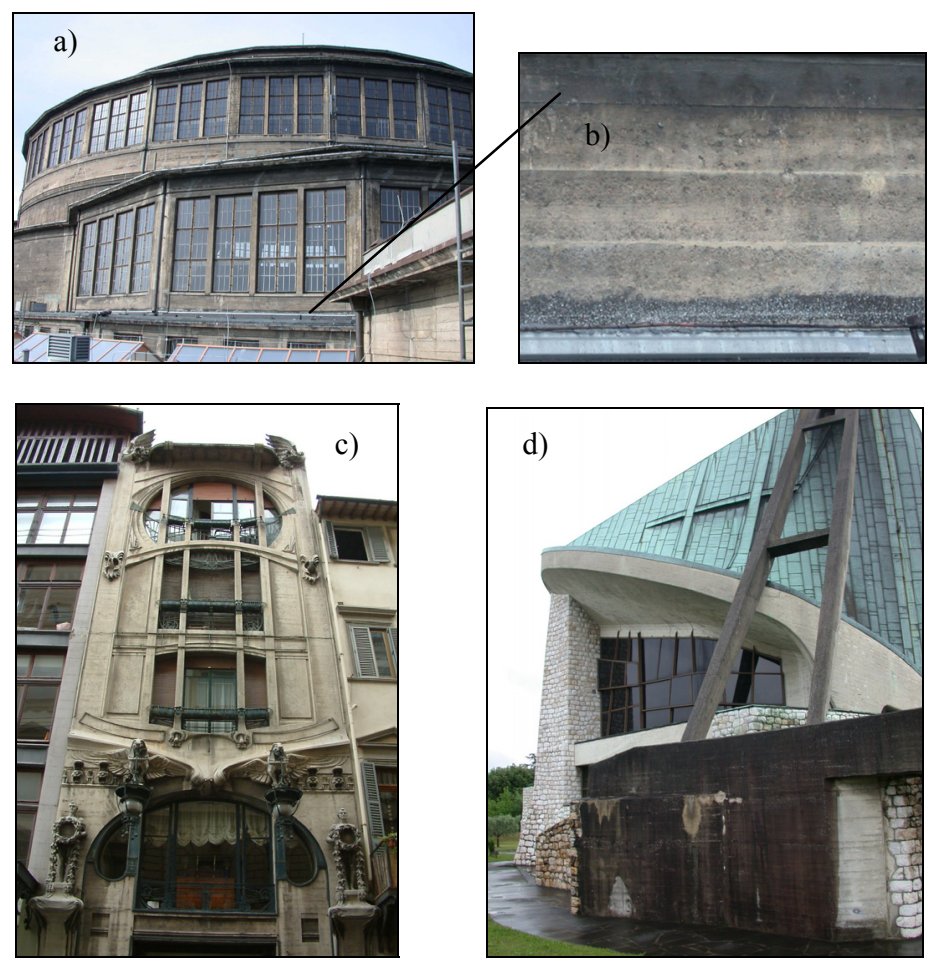

Figure 1: a) Centennial Hall, Wroclaw (Poland), b) dark damage layer in partly sheltered area on Centennial Hall, c) Casa Galleria Vichi, d) Chiesa dell'Autostrada del Sole.

The sampling sessions were performed taking into account the different levels of the buildings and the protection from rain: sheltered, partly sheltered and exposed part. The characterization of collected crust and cement mortar samples has been performed using a range of analytical methods. The structural, textural and petrographical properties were observed in transversal thin section by optical microscopy, utilizing an Olympus BX51 microscope. Morphological and elemental analyses of surface damage layers were performed by scanning electron microscope, equipped with dispersive energy analyser (SEM-EDX 
Philips XL 20). The crystalline phases of powdered samples were identified by X-ray diffractometer Philips PW 1730. Quantitative analysis of gypsum and carbonates was performed by means of differential thermal and thermogravimetric analysis (DTA-TGA), the instrument employed was a METTLER TOLEDO TGA/SDTA 851, equipped with a TSO $800 \mathrm{GC1}$ programmable gas switch. The anion concentration was measured by Ion Chromatography using DIONEX 4500i. The carbon fraction present in damage layers was discriminated and measured by combustion analysis (CHNSO) using a CHNSO EA 1108 FISONS Instruments analyser and following the methodology published by Ghedini et al. 2000 [6]. Following this methodology there were distinguished total carbon (TC) composed of carbonate carbon (CC) and noncarbonate carbon (NCC), which is in turn composed of elemental carbon (EC) and organic carbon (OC). The concentration of elements was determined using inductively coupled plasma - optical emission spectrometer (ICP-OES), Circular Optical System CIR.O.S.CCD.

\section{Results and discussion}

Optical microscopy observation performed on thin transversal section identified the presence of black damage layer in samples collected from Centennial Hall and Casa Galleria Vichi. The crusts formed at the surface of the two buildings
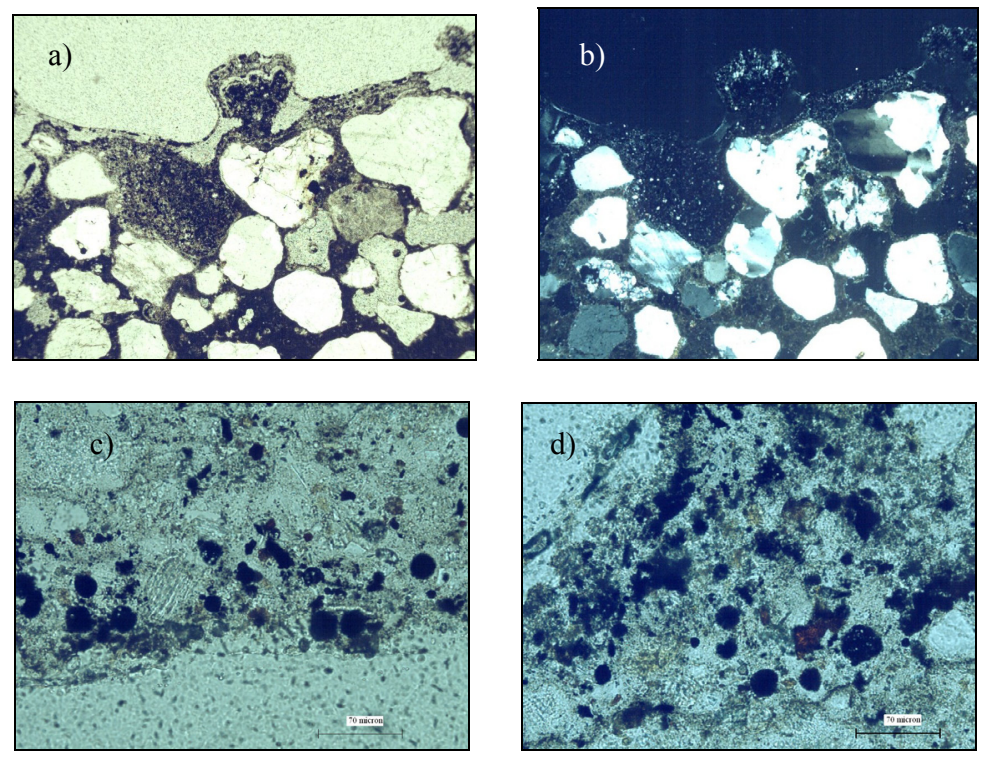

Figure 2: Optical micrograph a) planed-polarised light, b) cross-polarised light) of damage layer in partly sheltered area on Centennial Hall c), d) planed-polarised light, damage layer from Casa Galleria Vichi with embedded several black particles and iron oxides. 
are mainly composed of gypsum, quartz, iron oxides with embedded black and transparent particles (fig. 2a)). The black carbonaceous particles were frequently observed with diameter ranging from 13 to $30 \mu \mathrm{m}$ and in presence of smaller white or yellow transparent aluminosilicate particles $(5-7 \mu \mathrm{m})($ fig. $2 \mathrm{c}), \mathrm{d})$ ).

There were identified differences in thickness of the crusts. The crusts collected on the Centennial Hall (fig. 2a)) have irregular shape with higher thickness at sheltered surface $(200-600 \mu \mathrm{m})$ than at partly sheltered parts $(150$ $250 \mu \mathrm{m})$. The black damage layer formed on La Casa Galleria Vichi was much thinner, ranging from 130 to $290 \mu \mathrm{m}$ in sheltered areas. In case of samples from Chiesa dell'Autostrada del Sole the damage layer was not observed, probably due to recent restoration.

The SEM-EDAX analysis confirmed the presence of gypsum with laminar structure (fig. 3) in case of damage layer collected from the Centennial Hall and Casa Galleria Vichi. Along with gypsum, airborne particulate matter were frequently observed embedded in the damage layer. Spherical shape particles with smooth surface (fig. 4a)) and major elements such as silicon and aluminium followed by smaller amounts of $\mathrm{Ca}, \mathrm{S}, \mathrm{K}, \mathrm{Mg}, \mathrm{Fe}$, and $\mathrm{Ti}$ are typical of aluminosilicate particles from coal combustion [7]. Some of the aluminosilicate particles were covered by globular gypsum as it is shown in fig. 4b). There were also observed particles with spongy structure (fig. 4c)) characterized by $\mathrm{S}$ as a main element and $\mathrm{Ca}, \mathrm{Si}, \mathrm{Al}, \mathrm{Fe}, \mathrm{K}, \mathrm{Cl}, \mathrm{Mg}$ as minor elements typical for carbonaceous particles from oil combustion [8].

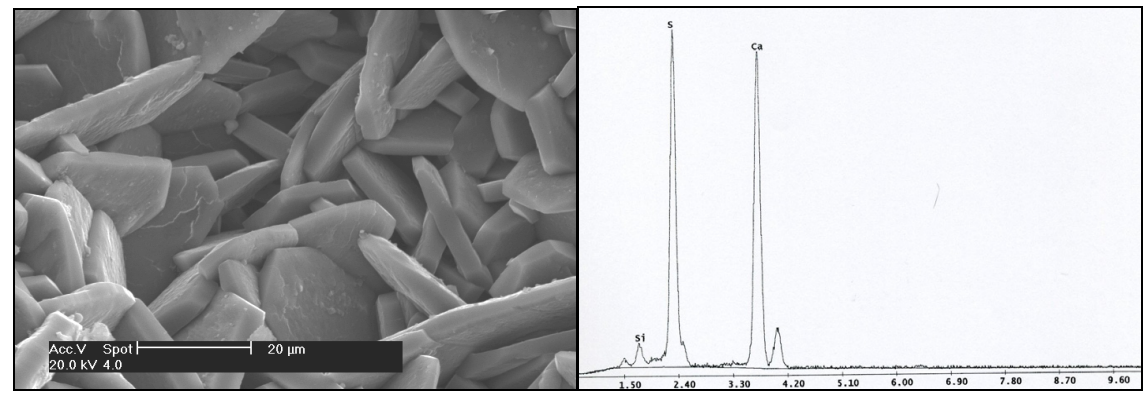

Figure 3: Scanning electron micrograph showing surface of damage layer composed of gypsum on the left, and relative EDX spectrum on the right from. Sample collected from the Centennial Hall.

The scanning electron micrograph of a sample from Chiesa dell'Autostrada del Sole presented in fig. 5 shows that surface is not covered by lamellar gypsum. The EDX analyses show that the main elements are $\mathrm{Si}, \mathrm{Ca}, \mathrm{Al}$ and $\mathrm{K}$, typical for Portland cement: that additionally confirms lack of sulfation process on the surface.

The x-ray diffraction analyses were performed on powdered sample of substrate and black crust. The analyses of material collected on the Centennial Hall indicate that quartz with tracers of calcite, portlandite, feldspar and mica are crystal phases characteristic for substrate. The mineralogical composition of the 
underlying material is ascribable to the aggregates and binder constituting the Portland Cement mortar used to build the Centennial Hall. The mineralogical phases identified only in black crusts are gypsum, as the main mineral, followed by hematite, ilmenite and rutile, which presence is connected to atmospheric deposition $[9,10]$.

The results from x-ray diffraction analyses of samples from Casa Galleria Vichi show that quartz and calcite are the main mineralogical phases associated with gypsum, feldspar, rutile, ilmenite and hematite. Quartz, calcite feldspar and trace of rutile (found only in substrate) belong to aggregates of concrete, while gypsum, ilmenite and hematite are related to air pollution deposition.

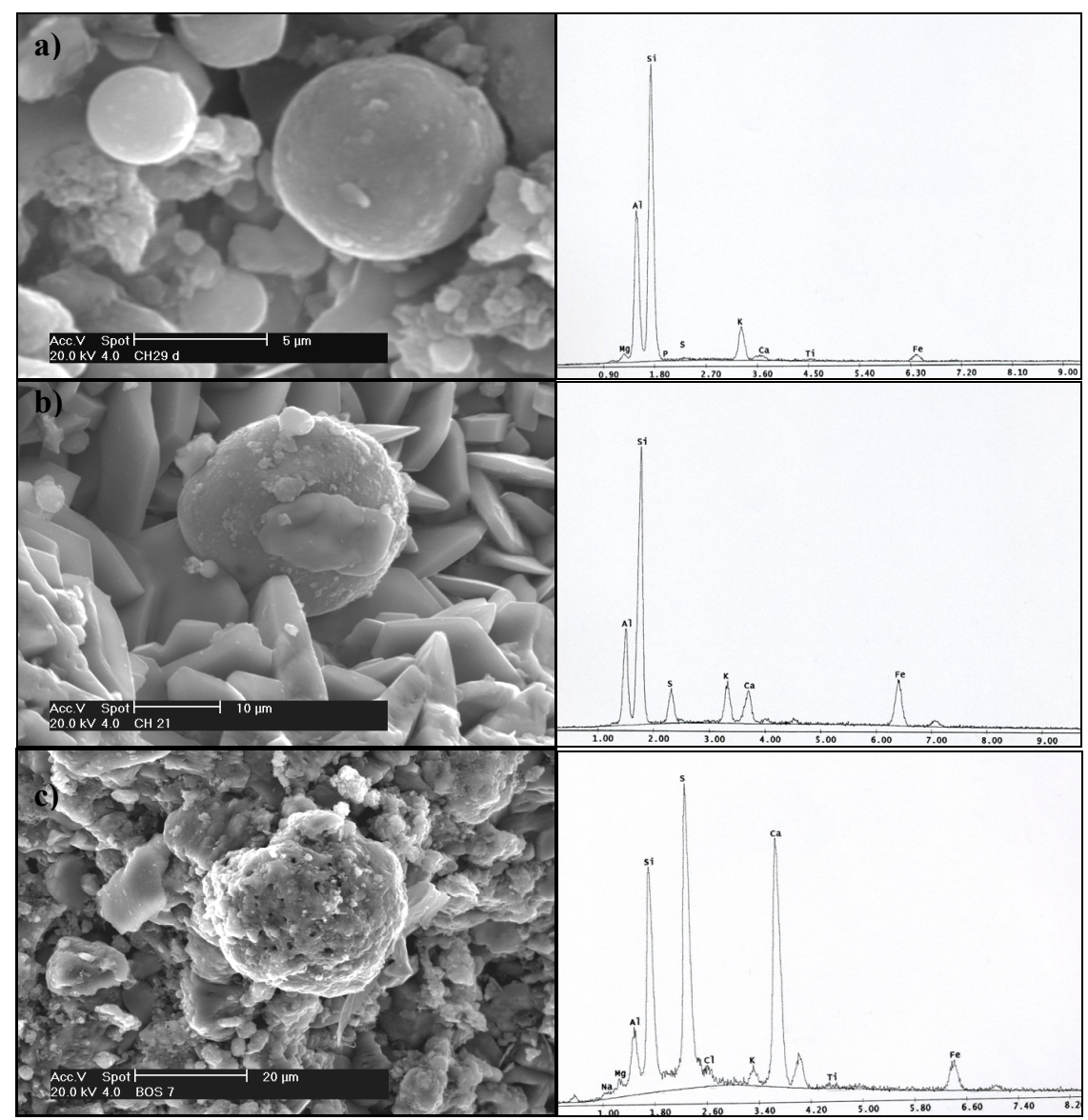

Figure 4: Scanning electron micrographs on the left with relative EDX on the right showing a) aluminosilicate particles, sample from Centennial Hall b) aluminosilicate particle cover by globular gypsum (Centennial Hall), c) carbonaceous particles embedded in gypsum matrix, sample collected from Casa Galleria Vichi. 


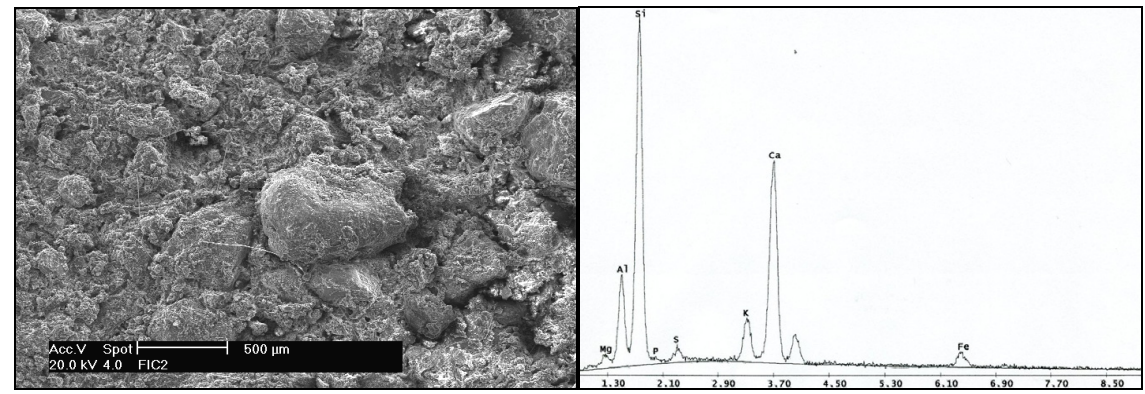

Figure 5: Scanning electron micrograph showing surface of sample from Chiesa dell'Autostrada del Sole, with relative EDX.

In both sites gypsum is the main crystal phase in damage layer, this confirms the results from optical and scanning electron microscope observation. Gypsum is the product of the interaction between atmospheric $\mathrm{SO}_{2}, \mathrm{SO}_{3}$ and $\mathrm{H}_{2} \mathrm{SO}_{4}$ and components of cement matrix.

Hematite, ilmenite and rutile in case of Centennial Hall are typical tracers of fly ash emitted into atmosphere by coal combustion [10]. The presence of hematite and ilmenite in Italian site is due to oil combustion in vehicular exhaust and domestic heating [11].

The quantitative analysis of gypsum and carbonates were performed by means of differential thermal and thermogravimetric analysis (DTA-TGA). The results (fig. 6) for representative samples of damage layer, from Centennial Hall and Casa Galleria Vichi, confirmed that gypsum is a major component of the

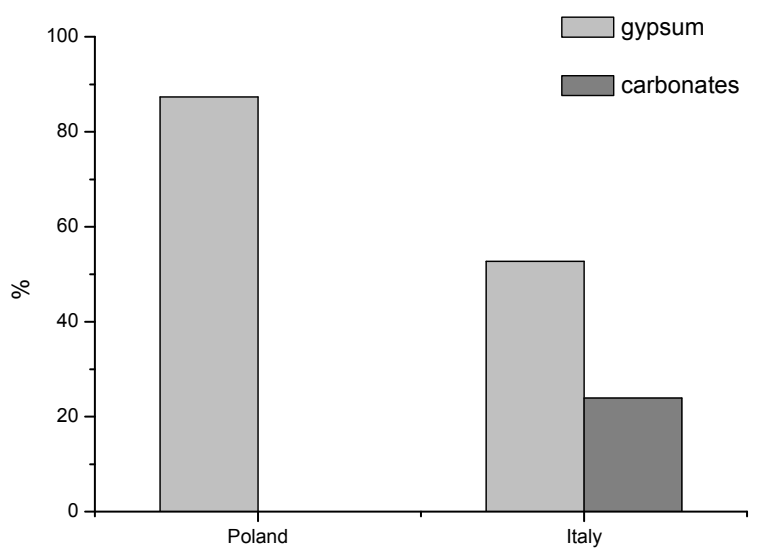

Figure 6: Gypsum and carbonates percentages (\%) measured by DTA-TGA in samples of black crust collected in Poland (Centennial Hall) and in Italy (Casa Galleria Vichi). 
black crusts. Comparing the two sites the highest concentration of gypsum (87\%) is observed in sample from Polish building. The carbonates were detected only in the damage layer from Casa Galleria Vichi.

The analyses performed by ion chromatography confirmed that sulphate $\left(\mathrm{SO}_{4}{ }^{=}\right)$is the most abundant anion in all samples containing damage layers (fig. 7), that underlines the importance of sulfation process in formation of black crusts.

The main sources of sulphur in the case of the Centennial Hall is coal power generation located in neighbourhood of the building and domestic combustion of fossil fuels burning. Taking into account the location of Casa Galleria, sulphate origin from domestic heating and vehicular exhaust. There were also detected considerable amounts of anions of organic acid such as formate, acetate and oxalate. The presence of organic anions is linked to primary and secondary pollutants and also biological weathering [10]. $\mathrm{NO}_{3}{ }^{-}$and $\mathrm{NO}_{2}{ }^{-}$were also found in lower concentration; there are closely connected to motor vehicles and industrial activity [3]. There were also found significant amount of $\mathrm{Br}^{-}$and $\mathrm{Cl}^{-}$, typical tracers of fossil fuel combustion $[11,12]$.

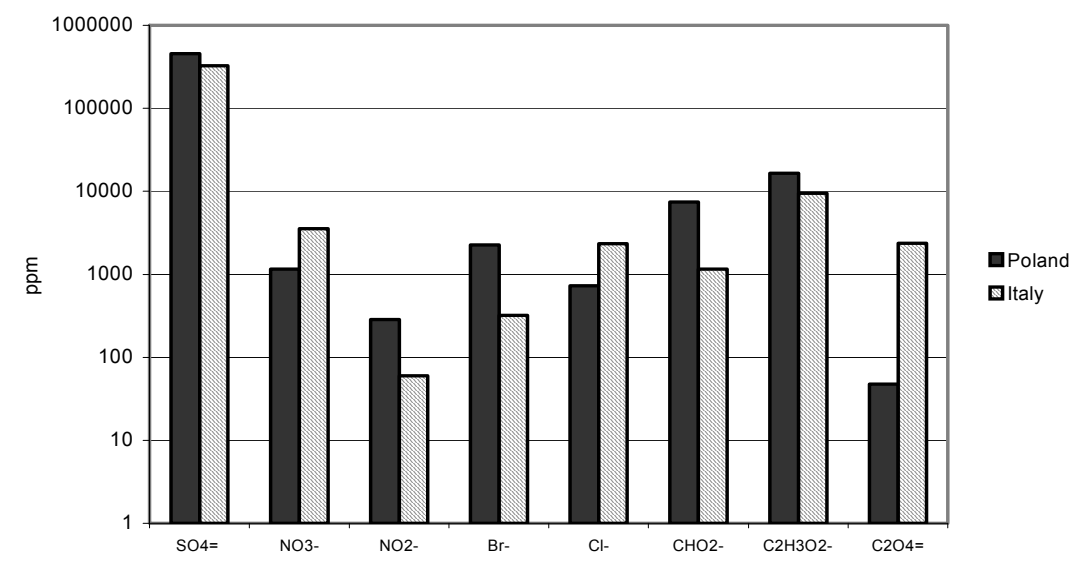

Figure 7: The results obtained by ion chromatography technique on black crust collected from building in Poland (Centennial Hall) and in Italy (Casa Galleria Vichi)

The discrimination of carbon contents in black crust during combustion analyses (CHNSO) shows differences between sample from Centennial Hall and Casa Galleria Vichi. The total carbon (TC) concentration in samples from Italian monument is ranging from $3,68 \%$ to $16,73 \%$ and this is higher than in samples from Poland, where maximum value of TC is $2,79 \%$. The TC in all samples from Poland has high contribution of noncarbonate carbon (NCC) (fig. 8a)), in sample representative for thick black crust the NCC is $90 \%$ of TC. The values of NCC in damage layer from Casa Galleria Vichi are very variable, in some sample the 
carbon carbonate (CC) fraction contribute for more than $30 \%$, that reflects the results from DTA-TGA, that carbonates were detected only in crusts from Casa Galleria Vichi. The non carbonate carbon (NCC) is composed of elemental carbon (EC) and organic carbon (OC) (fig. 8). The contribution of EC is higher than of organic carbon in all samples, the percentage fraction of EC in NCC is $91 \%$ in Polish sample of black crust, and $84 \%$ in Italian ones. The elemental carbon comes from combustion-generated aerosols deposited at building surface and embedded in damage layer [9]. The fact that is higher in the sample from Centennial Hall is connected to the fixed combustion source such as coal power station in neighbourhood of the building. The presence of organic carbon is linked to primary air pollutions coming from incomplete combustion of oil fossil fuel, secondary air pollutants and biological weathering. The higher percentage fraction of $\mathrm{OC}$ in samples from Casa Galleria Vichi is effect of the traffic emission in front of the building.

a)

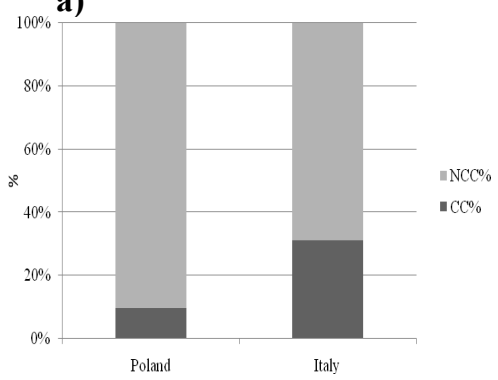

b)

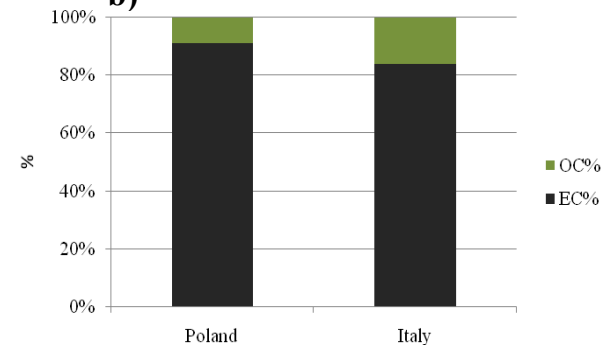

Figure 8: a) The non carbonate carbon (NCC) and carbonate carbon (CC) average percentage fraction of total carbon in samples representative of black crust collected from Centennial Hall (Poland) and Casa Galleria Vichi (Italy), b) The percentage fraction of organic carbon (OC) and elemental carbon (EC) of NCC.

The ICP-OES analyses identified elements such as $\mathrm{Al}, \mathrm{As}, \mathrm{Ca}, \mathrm{Cr}, \mathrm{Cu}, \mathrm{Fe}$, $\mathrm{Mg}, \mathrm{Mn}, \mathrm{Ni}, \mathrm{Pb}, \mathrm{S}, \mathrm{Sb}, \mathrm{Si}, \mathrm{Sn}, \mathrm{Sr}, \mathrm{Ti}, \mathrm{V}, \mathrm{Zn}$ in damage layers and substrate. The elaboration of data from ICP-OES allows, for the first time, to define enrichment factor $(\mathrm{EF})$ for cementitious materials. The enrichment factor indicates the association of the elements to the substrate or anthropogenic activity. In order to calculate the EF for an element $\mathrm{X}$, with respect to Aluminium, the following equation was used :

$$
E F(X)=\frac{[X]_{\text {blackcrust }} /[A l]_{\text {blackcrust }}}{[X]_{\text {substrate }} /[A l]_{\text {substrate }}},
$$

where $[\mathrm{X}]$ and $[\mathrm{Al}]$ represent the concentration of $\mathrm{X}$ and $\mathrm{Al}$ in the black crusts and substrate. Al was selected as a reference, as an element showing the small variation in underlying material and damage layers. There was accepted that if 
the value of $\mathrm{EF}>5$ we can consider the element $\mathrm{X}$ in the crust due to external sources, in particular atmospheric deposition, and not to the original building material $[13,14]$.

Table 1 presents elements with EF higher than 5 in the buildings under study.

Table 1: $\quad$ Elements with enrichment factor (EF) higher than 5.

\begin{tabular}{|l|l|}
\hline Site: & Elements with $\mathrm{EF}>5$ \\
\hline Centennial Hall & $\mathrm{As}, \mathrm{Cu}, \mathrm{Pb}, \mathrm{S}, \mathrm{Sn}, \mathrm{Zn}$ \\
\hline Casa Galleria Vichi & $\begin{array}{l}\mathrm{Ba}, \mathrm{Cd}, \mathrm{Co}, \mathrm{Cr}, \mathrm{Cu}, \mathrm{Fe} \mathrm{Pb} \mathrm{Ni}, \mathrm{S}, \mathrm{Sn}, \\
\mathrm{Ti}\end{array}$ \\
\hline Chiesa dell'Autostrada del Sole & $\mathrm{Cr}, \mathrm{Cu}, \mathrm{Ni}$ \\
\hline
\end{tabular}

Arsenic, which was found only in crust from Centennial Hall is a typical tracers of coal combustion, that confirms the impact of the coal power station located close to the monument. Sulfur and tin in Polish samples can have origin from coal combustion and vehicular exhaust, $\mathrm{Cu}, \mathrm{Pb}, \mathrm{Zn}$ are also attributed to traffic emission [11, 12].

The elements on the Casa Galleria Vichi: $\mathrm{Cd}, \mathrm{Co}, \mathrm{Cr}, \mathrm{Cu}, \mathrm{Fe}, \mathrm{Pb} \mathrm{Ni}, \mathrm{S}, \mathrm{Sn}, \mathrm{Ti}$ are coming for vehicular exhaust and in case of $\mathrm{Ba}, \mathrm{Co} \mathrm{Cr}$, Ni also from oil combustion in domestic heating $[11,12]$.

The $\mathrm{Cr} \mathrm{Cu}, \mathrm{Ni}$, in Chiesa dell'Autostrada del Sole, are attributed to vehicle emission.

\section{Conclusion}

Environmental damage in three European buildings from the XXth century architecture, caused by deposition of air multi-pollutants has been evaluated. The complete characterization of damage layers formed at cementitious monuments such as Centennial Hall, Casa Galleria Vichi, Chiesa dell'Autostrada del Sole was obtained for the first time.

The results show that gypsum, due to sulfation process, is the main damage product at surfaces sheltered from rain wash out, at Centennial Hall and Casa Galleria Vichi. The mineralogical observation and quantitative results showed that gypsum is more abundant in case of Centennial Hall than in Casa Galleria Vichi, this is directly linked to the location of the buildings. The Polish site represents one of the most polluted by $\mathrm{SO}_{2}$ region in Europe and additionally coal power station is in neighborhood of the building. Moreover, numerous carbonaceous and aluminosilicate particles were found embedded in gypsum matrix. It is known that carbonaceous particles are responsible for darkening of the surface and also play catalytic role in sulfation process. The presence of carbonaceous particles is ascribed to vehicle exhaust in both cases. The aluminosilicate particles have origin from coal combustion, that in case of Centennial Hall underlines the impact of coal power station and coal uses in domestic heating. 
The discrimination of carbon fractions showed also a difference in concentration of elemental and organic carbon depending on location. The Casa Galleria Vichi has higher organic carbon fraction, that is closely connected to traffic emission in front of the building.

Additionally, the elaboration of enrichment factor showed the origin of trace elements accumulated in the black crust, confirming that Casa Galleria Vichi is more affected by pollutants from vehicular emission and oil combustion from domestic heating, while Centennial Hall deterioration is mainly caused by multipollutants emitted by coal combustion.

The enrichment factor elaborations for Chiesa dell'Autostrada del Sole indicate presence of elemental tracers form vehicular emission. Gypsum has not been identified in the samples collected from this building. Even if this finding maybe connected to the decreasing concentration of $\mathrm{SO}_{2}$ in the last year, the restorations work "surface cleaning" frequently performed for the maintenance of the building should be considered.

The diagnosis of the damage process occurring on cementitious materials characterising modern architecture is fundamental for planning protection and conservation of the XXth century built heritage.

\section{Acknowledgements}

This work is performed within "European Ph.D. in Science for Conservation (EPISCON)", promoted by the European Commission with 6FP EU- Marie Curie EST Action, and also within the EC Project "Technologies and Tools to prioritise Assessment and diagnosis of air pollution impact on immovable and movable Cultural Heritage (TeACH)" (contract number: 212458)

\section{References}

[1] Marinoni, N., Pellizon Birelli, M., Rostagno, C., \& Pavese, A., The effects of atmospheric multipollutants on modern concrete. Atmospheric Environment, 37, pp. 4701-4712, 2003.

[2] Yates, T., Mechanism of air pollution damage to brick, concrete and mortar (Chapter 4). Topics in The Effects of Air Pollution on the Built Environment, ed. Brimblecombe, P., Imperial College Press, pp. 110-118, 2003.

[3] Zappia, G., Sabbioni, C., Riontino, C., Gobbi, G., \& Favoni, O., Exposure tests of building materials in urban atmosphere. The Science of the Total Environment, 224, pp. 235-244, 1998.

[4] Okochi, H., Kameda, H., Hasegava, S., Saito, N., Kubota, K., \& Igawa, M., Deterioration of concrete structures by acid deposition - an assessment of the role of rainwater on deterioration by laboratory and field exposure experiments using mortars specimens. Atmospheric Environment, 34, pp. 2937-2945, 2000. 
[5] Sabbioni, C., \& Zappia, G., Atmospheric-derived element tracers on damaged stone. The Science of the Total Environment, 126, pp. 35-48, 1992.

[6] Ghedini, N., Gobbi, G., Sabbioni, C., Zappia, G., Determination of elemental and organic carbon on damaged stone monuments. Atmospheric Environment, 34, pp. 4383-4391, 2000.

[7] Del Monte, M., \& Sabbioni, C., Morphology and mineralogy of fly ash from a coal-fueled power plant. Archives for Meteorology, Geophysics, and Bioclimatology, Series B35, pp. 93-104, 1984.

[8] Sabbioni, C. Contribution of atmospheric deposition to the formation of damage layers. The Science of the Total Environment, 167, pp. 49-55, 1995.

[9] Riontino, C., Sabbioni, C., Ghedini, N., Zappia, G., Gobbi, G., \& Favoni, O., Evaluation of atmospheric deposition on historic buildings by combined thermal analysis and combustion techniques. Thermochimica Acta, 321, pp. 215-222, 1998.

[10] Sabbioni, C., Ghedini, N., Bonazza, A., Organic anions in damage layer on monuments and buildings. Atmospheric Environment, 37, pp. 12611269,2003

[11] Querol, X., Alastuey, A., López-Soler, A., Mantilla, E., \& Plana, F., Mineral composition of atmospheric particulates around a large coal-fired power station. Atmospheric Environment, 30, pp. 3557-3572, 1996.

[12] Chen, Y., Shah, N., Huggins, F. E., \& Huffman, G.P., Investigation of the Microcharacteristics of $\mathrm{PM}_{2.5}$ in Residual Oil Fly Ash by Analytical Transmission Electron Microscopy, Environ. Sci. Technol., 38, pp 655365602004.

[13] Arditsoglou, A., \& Constantini, S., Levels of total suspended particulate matter and major trace elements in Kosovo a source identification and apportionment study. Chemosphere, 59, pp. 669-678, 2005.

[14] Gao, Y., Nelson, E.D., Field, M.P., Ding, Q., Li, H., Sherrell, R.M., Gigliotti, C.L., Van Ry, D.A., Glenn, T.R., \& Eisenreich, S.J., Characterization of atmospheric trace elements on PM2.5 particulate matter over the New York-New Jersey harbor estuary. Atmospheric Environment, 36, pp. 1077-1086, 2002. 